\title{
A Combination between Synthetic Unit Hydrograph (SCS) and Rational Method in a similar Conditions Water Shed
}

\author{
Neveen B. Abelmageed ${ }^{1}$, M. Hassan², Mona Fathi ${ }^{3}$, \\ ${ }^{1}$ Assoc. prof., Civil Engineering Department, Faculty of Engineering at Shoubra, University, Egypt \\ (Cairo,Egypt) \\ Email: neveenbadawy1975 [AT] gmail.com \\ ${ }^{2}$ Dr., Civil Engineering Department, Faculty of Engineering at Shoubra, University, Egypt \\ (Cairo, Egypt) \\ Email: mhassan1274 [AT] yahoo.com \\ ${ }^{3}$ B.Sc, Civil Engineering \\ (Cairo, Egypt) \\ Email: engmonafathi [AT] yahoo.com
}

\begin{abstract}
Studying watershed characteristics and choosing the most applicable methods to determine the amount of access rainfall that ran off is very important in many engineering applications, especially hydrology applications. That is to know the more suitable methods for protection against floods and to maximize benefits from the excess water. This study aims to establish a relation between the rational method and the SCS method. A subbasin in Wadi Dahab in Sinai, Egypt is investigated as a study area. To achieve the study aims, HEC-WMS software is chosen, which can analyze a watershed by using DEM and delineating basin. It calculates also important watershed parameters like area, runoff distances, and slope. The rainfall data is compiled and arranged. A statical analysis is executed to obtain the IDF curves. Hyfran-plus software is employed to locate the maximum depths for different return periods. Various values for the time of concentration are studied.

It is concluded that the difference between the rational and SCS methods is great for the time of concentration till 2 hours, then it decreases obviously from 2 till 6 hours. Also, it is concluded that the difference between the two methods is bigger for the small return periods of 2 and 5 years for all values of the time of concentration.

Employing the obtained equations, the peak runoff for one of the two methods (the rational and SCS methods) can be calculated knowing the time of concentration and the peak runoff for the second method.
\end{abstract}

Keywords: Wadi Dahab, HEC-WMS software, DEM, IDF curves, hyfran-plus software

\section{INTRODUCTION}

There are many suitable methods for protection against floods and to maximize benefits from excess water, [1]. The specifications of the watershed have an effective impact in estimating design floods and discharge. The inputs to the numerical models are the components of rainfall (period and intensity), type of soil, and land use. Any variation in these components could make instability in the model, [2].

Several models exist that can calculate watershed runoff. Each component of a model is an aspect of the rainfall-runoff process, such as precipitation, losses, and runoff transformation. Representing one of these components requires a set of parameters, which specify the characteristics of the watershed in the terms of their mathematical and empirical relation to physical processes. There are a lot of equations to specify the discharge of rainfall in the watershed that depends on a lot of criteria like area, landscape, and climate conditions. In this study, two methods were used; the SCS method and the rational method.

The Rational Method is widely used around the world and is simple to execute. The predictions of the peak flow do not represent the composite nature of the actual storms happening within a catchment. This concern Is particularly related to new stormwater management ways, which include united solutions involving slow drainage, harvesting, retention, and reuse of stormwater. [3].

The assessment of the amount of runoff using the SCS-CN method could be used in watershed management effectively. This method was used in the region Gudiyattam Block, Vellore District, Tamil Nadu in India, and the results from the monthly runoff and seasonal runoff data showed that it could be studied for dependable accuracy along with the locative variation of land use and soil type, [4]. 
The difference between the two methods SCS and rational method was studied by applying both of them in the Khoshehaye Zarrin watershed in Iran, which did not have any hydrometry gauges. Firstly, the run-off coefficient and rainfall intensity in each sub-basin were calculated with the Rational method, then by curve number, and the peak flow was calculated to each sub-basin. After that, the dimensionless unit hydrograph was drawn, and the results were compared with the nearest gauge. The results revealed that the SCS method had accurate estimation than the Rational method and it could be used for peak flow estimation in similar condition watersheds, [5].

\section{STUDY AREA}

Wadi Dahab lies in Sinai, Egypt, as shown in Figure 1, [6]. It is composed of 7 sub-basins, from them one sub-basin is chosen to be the study area (Wadi Abu Khshieb), as shown in Figure 2, [6].

Wadi Dahab is composed of deposits, terraces, and alluvial fans that cover approximately $17 \%$ of the total area. About $13 \%$ of the area is sedimentary succession representing the age from upper Cretaceous to Cambrian. Primarily igneous and metamorphic rocks exist in $7 \%$ of the area. The igneous rocks exist in $63 \%$ of the area of the Wadi Watershed, [7], as shown in Table 1 and Fig. 3.

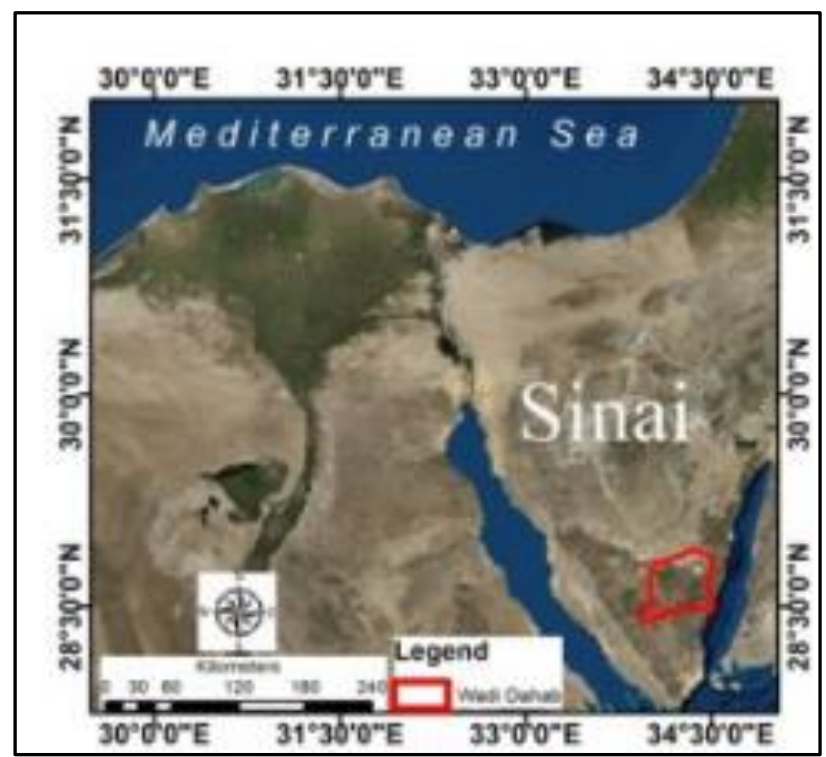

Fig.1 Location of Wadi Dahab Basin, Sinai, Egypt

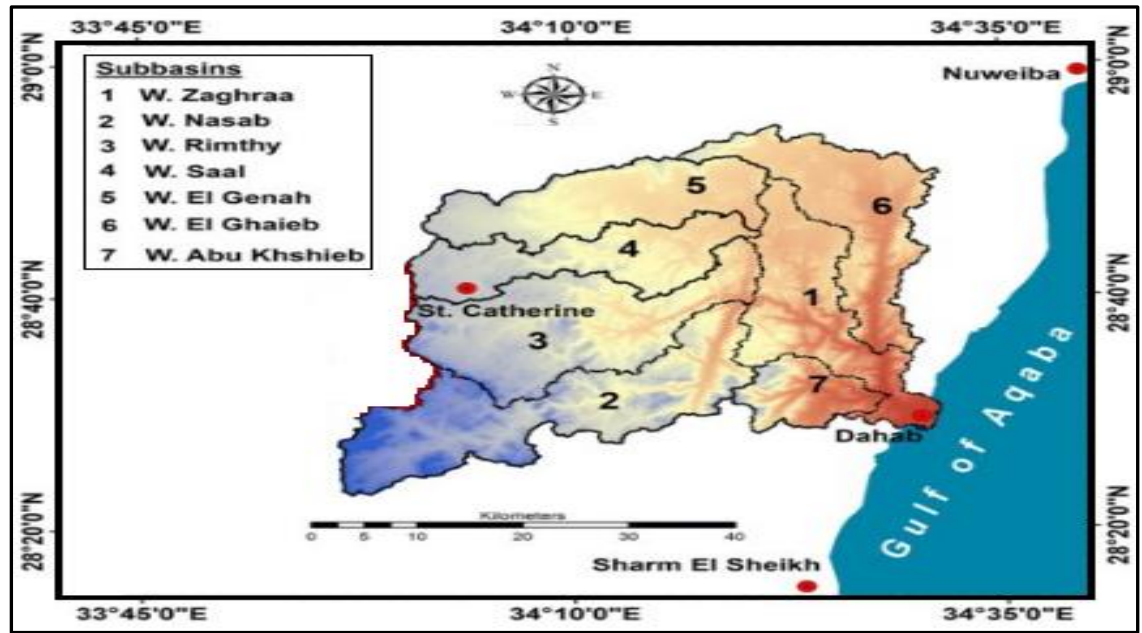

Fig.2 Study Area, Wadi Abu Khshieb, Wadi Dahab Basin 
Table 1. The Geology Components in Wadi Dahab

\begin{tabular}{|l|c|}
\hline \multicolumn{1}{|c|}{ Land Cover } & Percentage \\
\hline Terraces, and alluvial fans & $17 \%$ \\
\hline Sedimentary succession & $13 \%$ \\
\hline Primarily igneous and metamorphic rocks & $7 \%$ \\
\hline Igneous rocks & $63 \%$ \\
\hline
\end{tabular}

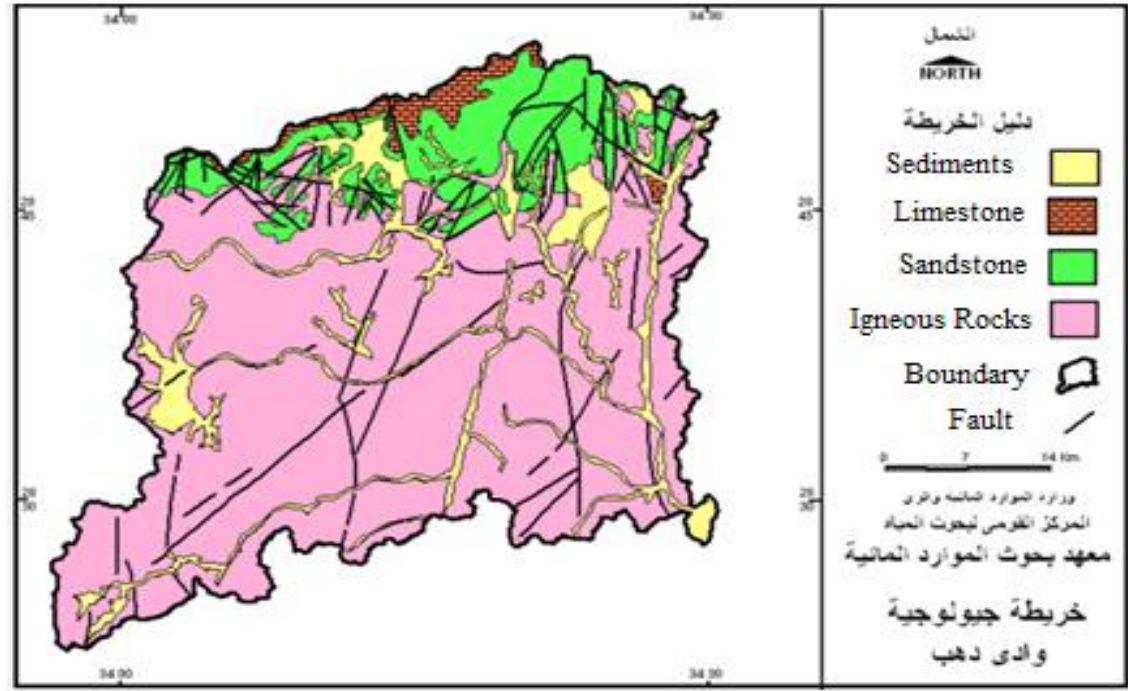

Fig.3 Geologic Map of Wadi Dahab Basin

The catchment area to the selected subbasin was delineated and calculated using a computer software WMS (Watershed Modeling System) to equal $30.13 \mathrm{~km}^{2}$. It has a general slope of $0.0531 \mathrm{~m} / \mathrm{m}$, the basin length along the main channel from outlet to upstream boundary equal 12,155.14 meters, and the maximum flow (watercourse) length equal 10,525.99 meters

To simulate the rainfall-runoff process using WMS software, the data is assumed to accommodate the characteristics of Egypt's climate especially the Wadi Dahab climate, [8], which is described as an arid climate with high rainfall intensity during winters. The data fit rainfall distribution type II.

\section{MATERIAL AND METHOD}

To achieve the aim of the study the following steps have been followed:

- The rainfall data is compiled and arranged for 35 years (from 1980 to 2015) and it fit rainfall distribution type II.

- Gumbel distribution methodology is followed to perform the flood probability analysis and calculate the rainfall Intensity-Duration-Frequency (IDF) relationship.

- Hyfran-plus software is used to estimate the maximum depth according to each return period using the maximum annual rainfall depth.

- The coefficient of runoff $(\mathrm{C})$ and the Curve Number $(\mathrm{CN})$ are chosen according to land use, topography, soil type, vegetal cover, and moisture content of the soil.

- $\quad$ HEC-WMS software is used to delineate the watershed and calculate the discharge for many values of time of concentration.

- $\quad$ DEM (Digital Elevation Model) is used and processed by WMS to delineate the Wadi Dahab watershed and calculate the hydrological parameters.

\section{RAINFALL DATA ANALYSIS}

The estimation of IDF curves is based on rainfall data including maximum daily rainfall depths data during the period 1980-2015, as shown in Table 2. 
Table 2. Maximum Daily Rainfall Depths During 1980-2015

\begin{tabular}{|l|l|c|l|l|c|}
\hline No. & Year & $\begin{array}{c}\text { Max Daily Rainfall during } \\
\text { a Year, mm }\end{array}$ & No. & Year & $\begin{array}{c}\text { Max Daily Rainfall during } \\
\text { a Year, mm }\end{array}$ \\
\hline 1 & 1980 & 14.50 & 19 & 1998 & 44.20 \\
\hline 2 & 1981 & 17.50 & 20 & 1999 & 62.21 \\
\hline 3 & 1982 & 18.10 & 21 & 2000 & 26.60 \\
\hline 4 & 1983 & 19.55 & 22 & 2001 & 56.15 \\
\hline 5 & 1984 & 33.50 & 23 & 2002 & 49.35 \\
\hline 6 & 1985 & 30.50 & 24 & 2003 & 33.00 \\
\hline 7 & 1986 & 35.00 & 25 & 2004 & 18.00 \\
\hline 8 & 1987 & 36.22 & 26 & 2005 & 20.00 \\
\hline 9 & 1988 & 22.66 & 27 & 2006 & 37.90 \\
\hline 10 & 1989 & 55.60 & 28 & 2007 & 16.50 \\
\hline 11 & 1990 & 60.20 & 29 & 2008 & 22.00 \\
\hline 12 & 1991 & 60.30 & 30 & 2009 & 15.00 \\
\hline 13 & 1992 & 40.22 & 31 & 2010 & 24.33 \\
\hline 14 & 1993 & 60.20 & 32 & 2011 & 22.32 \\
\hline 15 & 1994 & 45.60 & 33 & 2012 & 24.20 \\
\hline 16 & 1995 & 45.80 & 34 & 2013 & 25.20 \\
\hline 17 & 1996 & 41.00 & 35 & 2014 & 22.55 \\
\hline 18 & 1997 & 40.00 & 36 & 2015 & 22.50 \\
\hline
\end{tabular}

According to Dakheel, [9], the probability examination of the rainfall Gumbel distribution was employed. This theory is the most popular distribution for IDF analysis owing to its suitability for modeling the maximum. It is simple and uses only maximum values or peak rainfalls. The Gumbel distribution calculates the 2, 5, 10, 20, 50,100, and 200 years return intervals for each duration period and requires several calculations. Frequency rainfall PT (mm) for every return period Tr (year) for every duration is represented by:

$\mathrm{P}_{\mathrm{t}}=\mathrm{P}_{\mathrm{avg}}+\left(\mathrm{K}_{\mathrm{t}} * \mathrm{~S}\right)$

Where $\mathrm{K}_{\mathrm{t}}$ is the Gumbel frequency factor that is given by:

$$
K_{t}=-\frac{\sqrt{6}}{\pi}\left\{0.5772+\ln \left[\ln \left(\frac{T_{r}}{T_{r}-1}\right)\right]\right\}
$$

And $\mathrm{P}_{\mathrm{avg}}$ is the average of the highest rainfall corresponding to a precise duration. Gumbel's distribution of the arithmetic average in Equation 2 is used as follows:

$$
p_{\text {avg }}=\frac{1}{n} \sum_{i=1}^{n} p_{t}
$$

Where $n$ is the number of events or years of record.

The standard deviation $\mathrm{S}$ is calculated by:

$S=\sqrt{\frac{\left(p^{-}-p_{a v g}\right)^{2}}{n-1}}$

Where $p^{-}$is the maximum rainfall depth corresponding to a precise duration.

The rainfall intensity $(\mathrm{mm} / \mathrm{hr})$ for a return period is represented by:

$I_{t}=\frac{p_{t}}{t_{d}}$

Where $t_{d}$ is the duration in hours.

The obtained values of standard deviation are illustrated in Table 3, and the values for Gumbel frequency factors are shown in Table 4 . The computed values of rainfall intensity $\left(\mathrm{I}_{\mathrm{t}}\right)$ in $\mathrm{mm} / \mathrm{hr}$ are tabulated in Table 5 for different return periods.

The obtained IDF curves are illustrated in Fig. 4. 
Table 3. The values of Standard Deviation (S) and the Average Precipitation ( $\left.\mathrm{P}_{\text {avg }}\right)$

\begin{tabular}{|c|c|c|c|c|c|c|c|c|c|c|c|}
\hline $\begin{array}{c}\text { Duration, } \\
\text { hr }\end{array}$ & $\mathbf{0 . 1}$ & $\mathbf{0 . 3}$ & $\mathbf{1 . 0}$ & $\mathbf{2 . 0}$ & $\mathbf{3 . 0}$ & $\mathbf{8 . 0}$ & $\mathbf{9 . 0}$ & $\mathbf{1 0 . 0}$ & $\mathbf{1 0 . 5}$ & $\mathbf{1 1 . 0}$ & $\mathbf{1 1 . 5}$ \\
\hline $\mathbf{S}$ & 73.87 & 25.00 & 7.86 & 4.11 & 3.15 & 1.82 & 1.67 & 1.51 & 1.43 & 1.38 & 1.29 \\
\hline Pavg & 68.90 & 23.80 & 7.62 & 4.26 & 3.29 & 2.10 & 2.05 & 1.92 & 1.86 & 1.85 & 1.83 \\
\hline $\begin{array}{c}\text { Duration, } \\
\text { hr }\end{array}$ & $\mathbf{1 2 . 0}$ & $\mathbf{1 2 . 5}$ & $\mathbf{1 3 . 0}$ & $\mathbf{1 3 . 5}$ & $\mathbf{1 4 . 0}$ & $\mathbf{1 4 . 5}$ & $\mathbf{1 5 . 0}$ & $\mathbf{1 8 . 0}$ & $\mathbf{2 0 . 0}$ & $\mathbf{2 2 . 0}$ & $\mathbf{2 4 . 0}$ \\
\hline S & 1.20 & 1.15 & 1.09 & 1.01 & 0.98 & 0.96 & 0.95 & 0.81 & 0.75 & 0.66 & 0.61 \\
\hline P avg & 1.81 & 1.80 & 1.78 & 1.77 & 1.76 & 1.76 & 1.74 & 1.66 & 1.51 & 1.43 & 1.41 \\
\hline
\end{tabular}

Table 4. The values of Gumbel Frequency Factor

\begin{tabular}{|l|l|}
\hline \multicolumn{1}{|c|}{ Tr, years } & \multicolumn{1}{c|}{$\mathbf{K}_{\mathbf{t}}$} \\
\hline 2 & -0.164 \\
\hline 5 & 0.719 \\
\hline 10 & 1.305 \\
\hline 20 & 1.866 \\
\hline 50 & 2.592 \\
\hline 100 & 3.137 \\
\hline 200 & 3.679 \\
\hline
\end{tabular}

Table 5. Computed Intensity $\left(\mathrm{I}_{\mathrm{t}}\right)$ in $(\mathrm{mm} / \mathrm{h})$ (Gumbel distribution)

\begin{tabular}{|c|c|c|c|c|c|c|c|}
\hline \multirow{2}{*}{$\mathbf{T}_{\mathbf{r}(\mathbf{m i n})}$} & \multicolumn{7}{|c|}{$\boldsymbol{I}_{\boldsymbol{t}}(\mathbf{y})$} \\
\cline { 2 - 8 } & $\mathbf{2}$ & $\mathbf{5}$ & $\mathbf{1 0}$ & $\mathbf{2 0}$ & $\mathbf{5 0}$ & $\mathbf{1 0 0}$ & $\mathbf{2 0 0}$ \\
\hline 6 & 56.86 & 122.15 & 165.37 & 206.84 & 260.51 & 300.73 & 340.80 \\
\hline 18 & 19.70 & 41.80 & 56.43 & 70.46 & 88.62 & 102.24 & 115.80 \\
\hline 60 & 6.33 & 13.28 & 17.88 & 22.29 & 28.01 & 32.29 & 36.55 \\
\hline 120 & 3.59 & 7.23 & 9.64 & 11.95 & 14.94 & 17.18 & 19.41 \\
\hline 180 & 2.77 & 5.56 & 7.40 & 9.17 & 11.47 & 13.18 & 14.89 \\
\hline 480 & 1.80 & 3.42 & 4.49 & 5.51 & 6.84 & 7.84 & 8.83 \\
\hline 540 & 1.78 & 3.26 & 4.24 & 5.19 & 6.41 & 7.32 & 8.23 \\
\hline 600 & 1.68 & 3.02 & 3.90 & 4.75 & 5.84 & 6.67 & 7.49 \\
\hline 630 & 1.63 & 2.90 & 3.73 & 4.54 & 5.57 & 6.35 & 7.13 \\
\hline 660 & 1.63 & 2.85 & 3.66 & 4.44 & 5.44 & 6.19 & 6.94 \\
\hline 690 & 1.61 & 2.76 & 3.51 & 4.24 & 5.18 & 5.88 & 6.59 \\
\hline 720 & 1.61 & 2.68 & 3.39 & 4.07 & 4.95 & 5.60 & 6.26 \\
\hline 750 & 1.61 & 2.63 & 3.31 & 3.95 & 4.79 & 5.42 & 6.04 \\
\hline 780 & 1.60 & 2.57 & 3.21 & 3.82 & 4.61 & 5.21 & 5.80 \\
\hline 810 & 1.60 & 2.50 & 3.10 & 3.67 & 4.41 & 4.96 & 5.51 \\
\hline 840 & 1.60 & 2.47 & 3.05 & 3.60 & 4.31 & 4.85 & 5.38 \\
\hline 870 & 1.60 & 2.46 & 3.02 & 3.56 & 4.27 & 4.79 & 5.32 \\
\hline 900 & 1.59 & 2.46 & 2.99 & 3.53 & 4.22 & 4.74 & 5.26 \\
\hline 1080 & 1.53 & 2.43 & 2.73 & 3.19 & 3.78 & 4.22 & 4.66 \\
\hline 1200 & 1.39 & 2.25 & 2.50 & 2.92 & 3.46 & 3.87 & 4.28 \\
\hline 1320 & 1.33 & 2.06 & 2.30 & 2.68 & 3.16 & 3.52 & 3.88 \\
\hline 1440 & 1.31 & 1.92 & 2.21 & 2.56 & 3.00 & 3.34 & 3.67 \\
\hline & & & & & & & \\
\hline
\end{tabular}




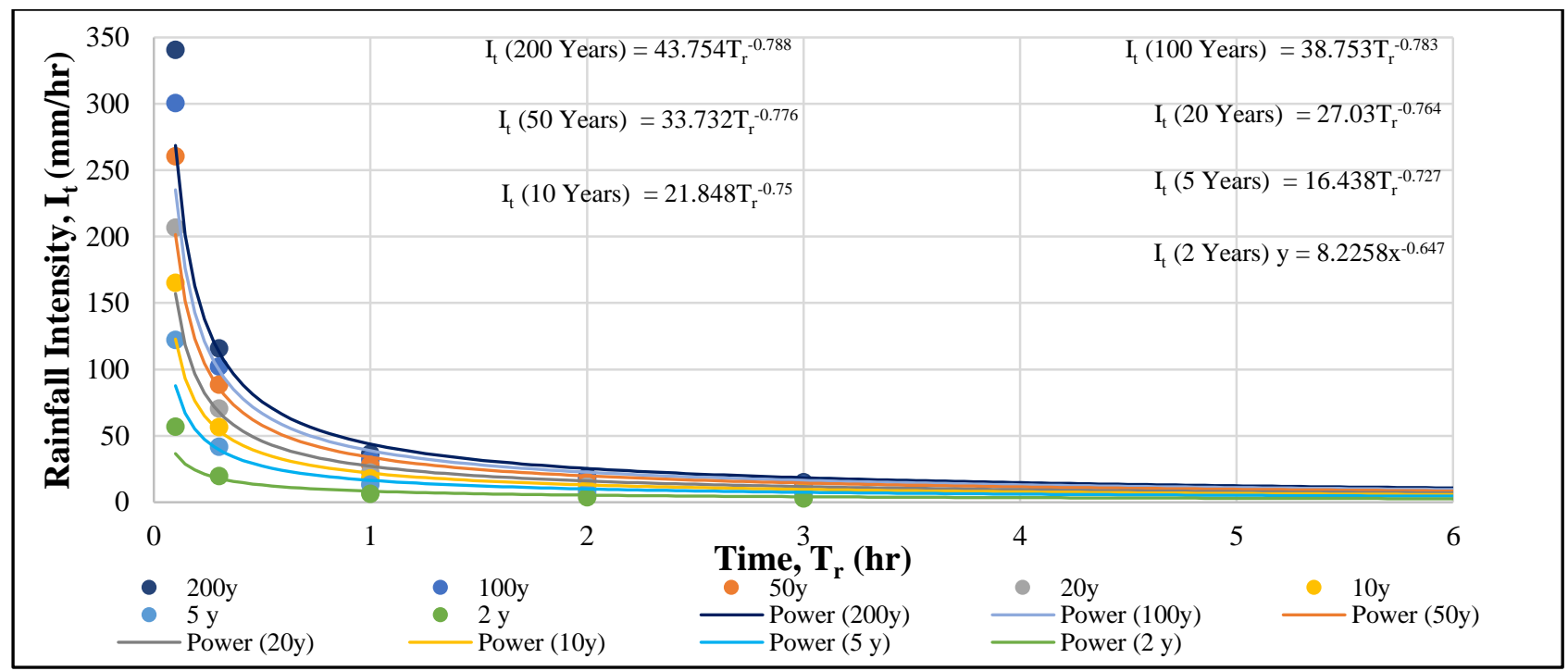

Fig 4. IDF Curves at Study Area

To estimate the maximum depth according to each return period, hyfran-plus software is used to employ the yearly maximum daily rainfall, as illustrated in Fig. 5.

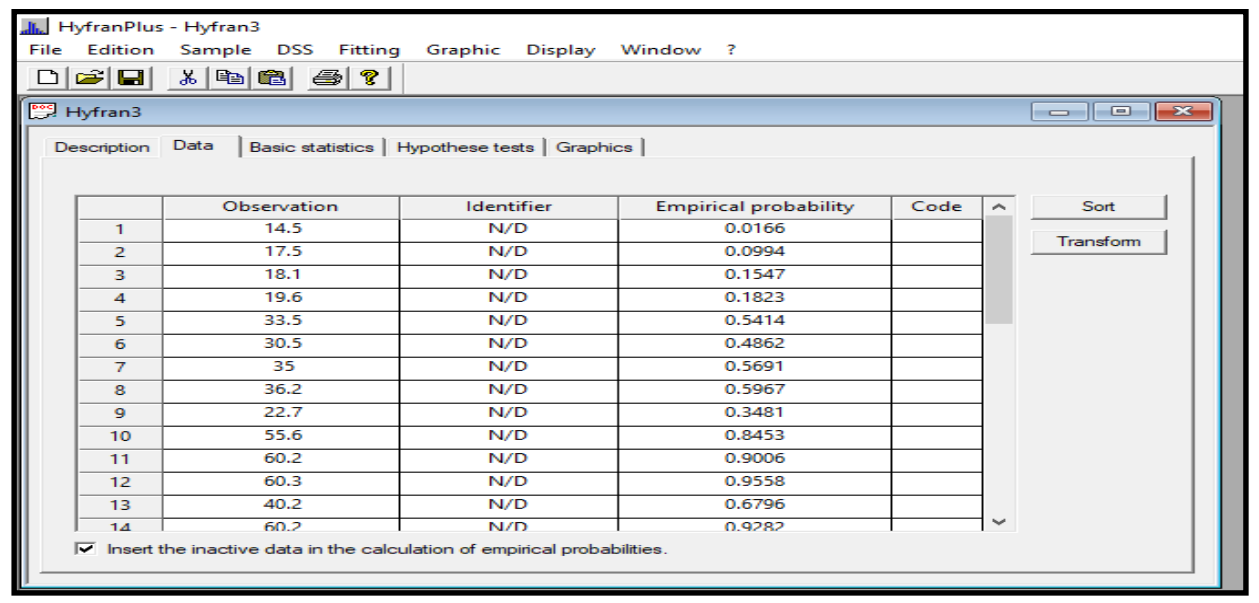

Fig. 5 Data in Hyfranplus Software

The obtained results showed that the pattern parameter of the Gamma distribution is the most suitable distribution as it has the lowest values of (BIC) and (AIC) parameters, as shown in Fig. 6.

The Gamma distribution is shown in Fig. 7. The maximum rainfall depths are tabulated in Table 6 for different return periods.

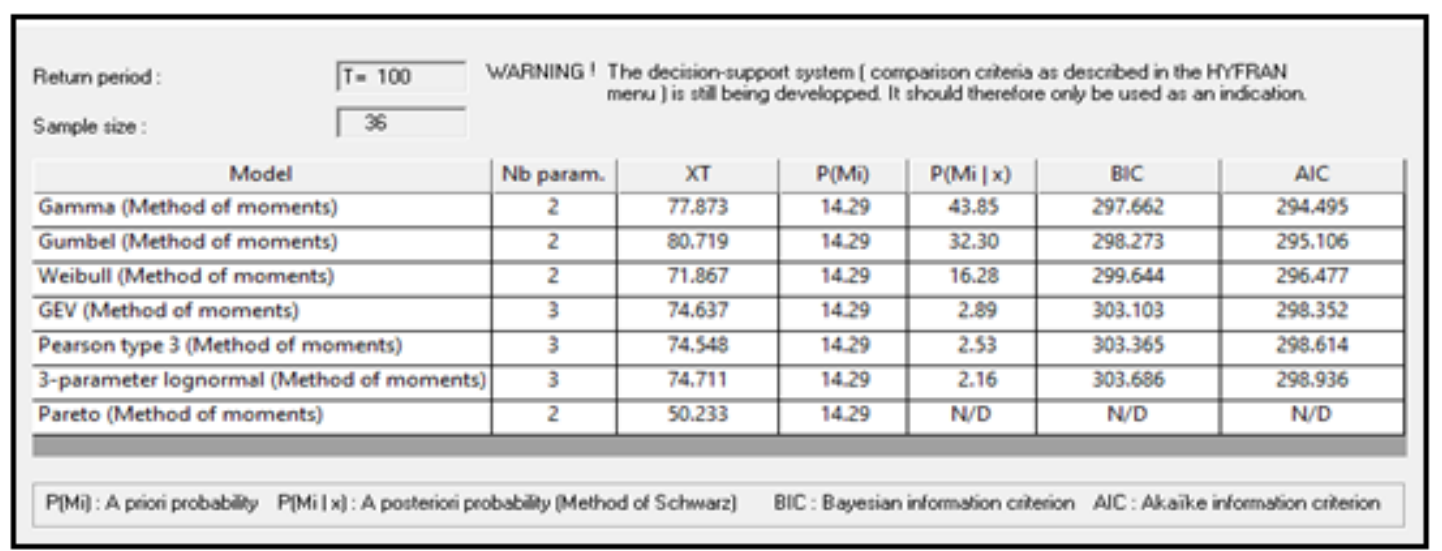

Fig. 6 Employed Methods by Hyfranplus Software 


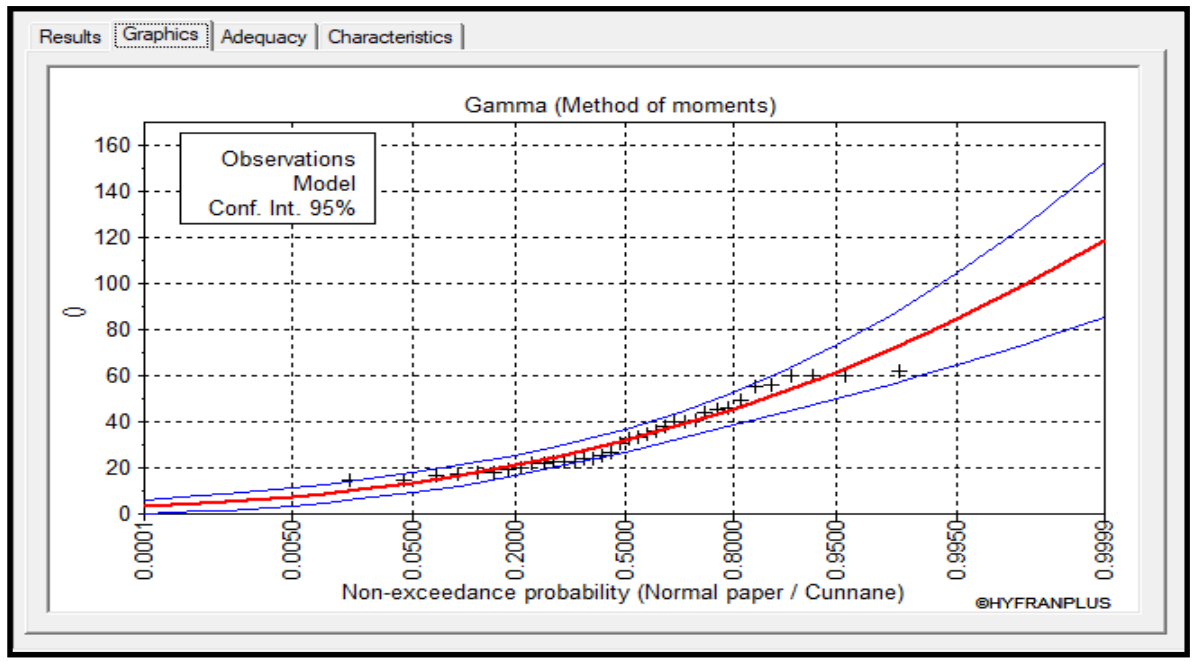

Fig. 7 Gamma Distribution

Table 6. The Maximum Rainfall Depths (mm)

\begin{tabular}{|l|l|}
\hline Return Period, Year & \multicolumn{1}{c|}{$\mathbf{d}_{\max }, \mathbf{m m}$} \\
\hline 200 & 84.4 \\
\hline 100 & 77.9 \\
\hline 50 & 71.1 \\
\hline 20 & 61.6 \\
\hline 10 & 53.8 \\
\hline 5 & 45.4 \\
\hline 2 & 31.7 \\
\hline
\end{tabular}

\section{RESULTS AND DISCUSSION}

For every studied return period, the peak runoff is obtained employing the rational and SCS methods. The percentage ratio of the difference between the rational and SCS methods with respect to the rational method is calculated for three intervals for the time of concentration; $0-2,2-4$, and $4-6$ hours. The percentage ratio of the difference is plotted versus the time of concentration. Regression analyses are performed and equations are obtained to relate the difference with the time of concentration for the three intervals of the time of concentration.

\subsection{At Return Period 200 Years}

Figure 8 illustrates the difference between the rational and SCS methods till 6 hours for the return period of 200 years. From the figure, it is found that the difference is great and decreases obviously for the time of concentration till 2 hours. For the time of concentration from 2 to 6 hours, the difference between the two methods is small ( $\pm 5 \%)$. It is found that the difference is zero at the time of concentration of 2.66 hours. 


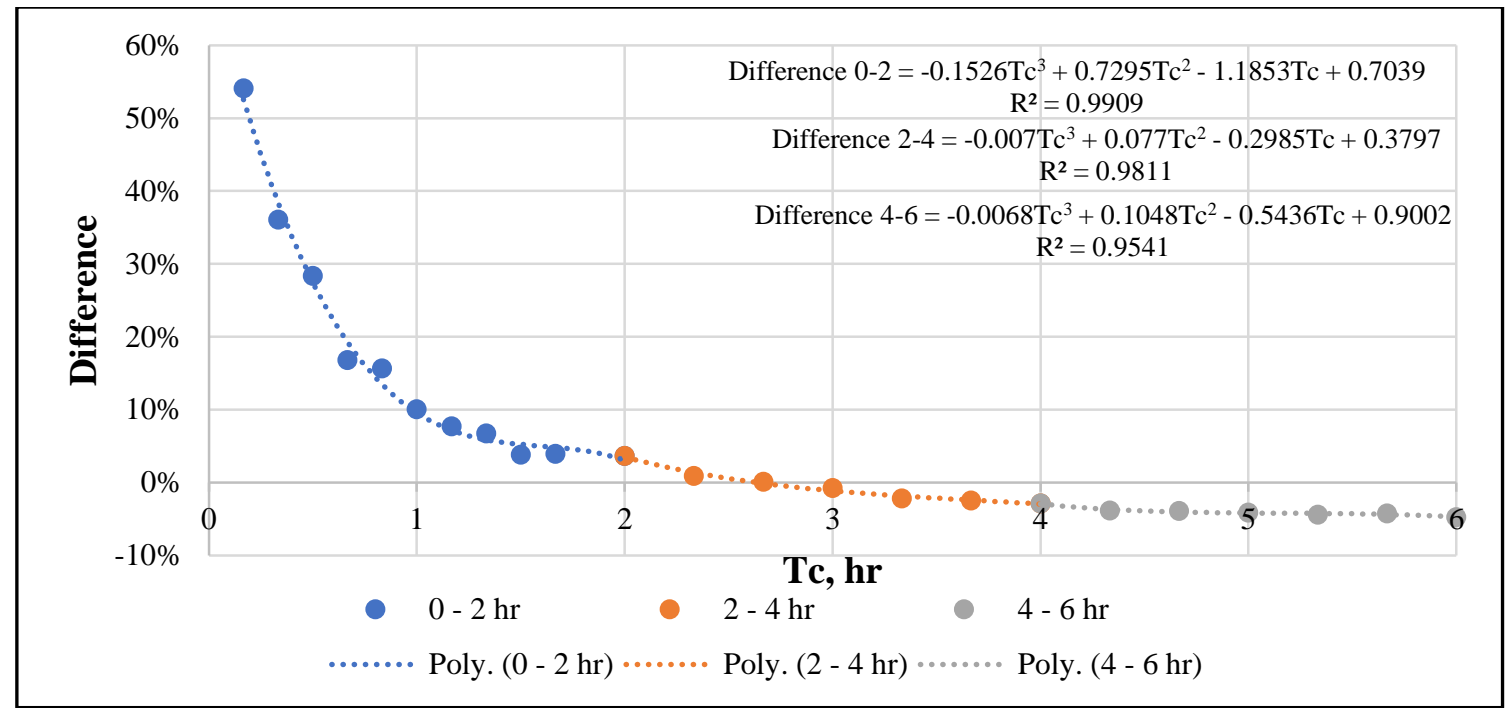

Fig 8. The Difference Till 6 hours at Return Period 200 Years

\subsection{At Return Period 100 Years}

Figure 9 illustrates the difference between the rational and SCS methods till 6 hours for the return period of 100 years. From the figure, it is found that the difference is great and decreases obviously for the time of concentration till 2 hours. For the time of concentration from 2 to 6 hours, the difference between the two methods is small (-3\%: 5\%). It is found that the difference is zero at the time of concentration of 2.96 hours.

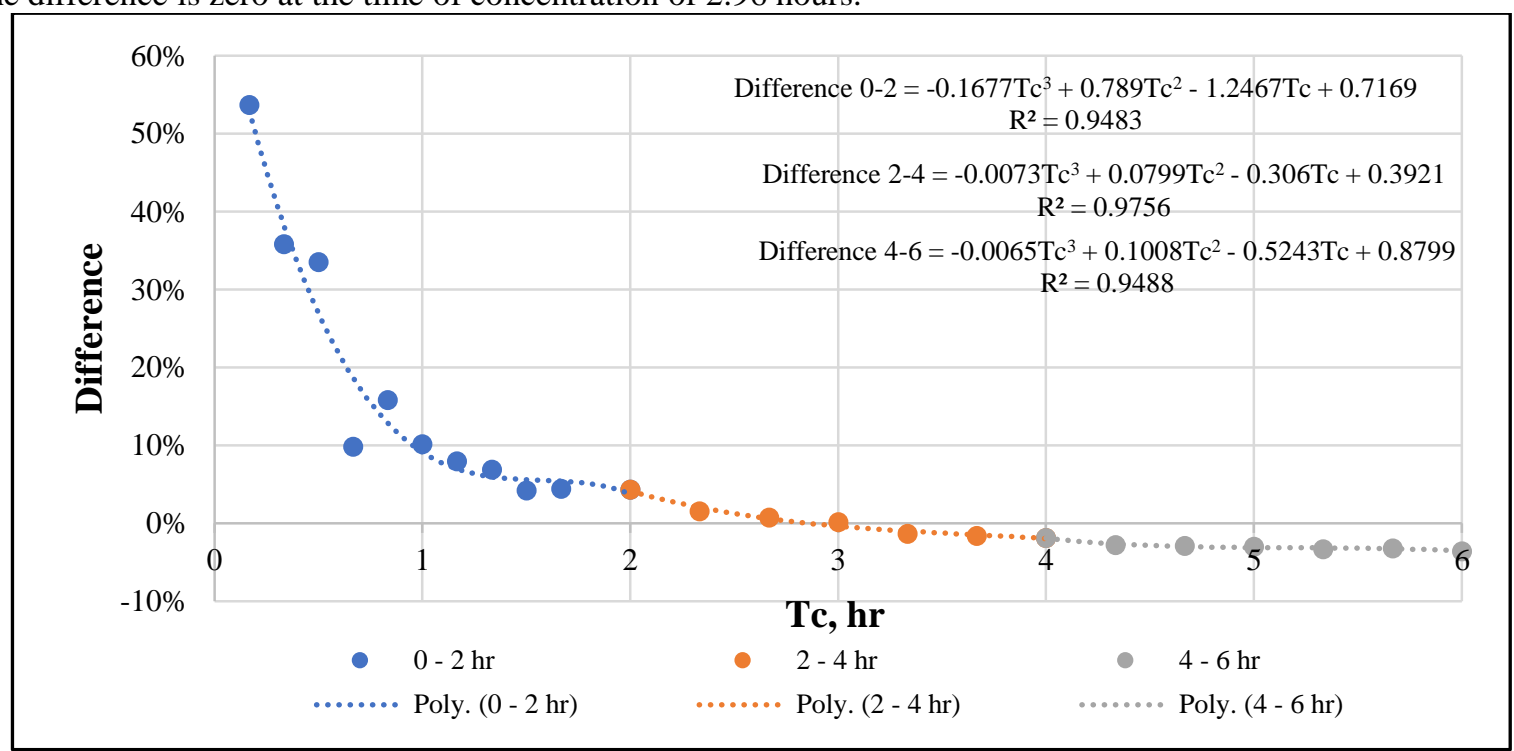

Fig 9. The Difference Till 6 hours at Return Period 100 Years

\subsection{At Return Period 50 Years}

Figure 10 illustrates the difference between the rational and SCS methods till 6 hours for the return period of 50 years. From the figure, it is found that the difference is great and decreases obviously for the time of concentration till 2 hours. For the time of concentration from 2 to 6 hours, the difference between the two methods is small $(-2 \%: 5 \%)$. It is found that the difference is zero at the time of concentration of 3.78 hours. 


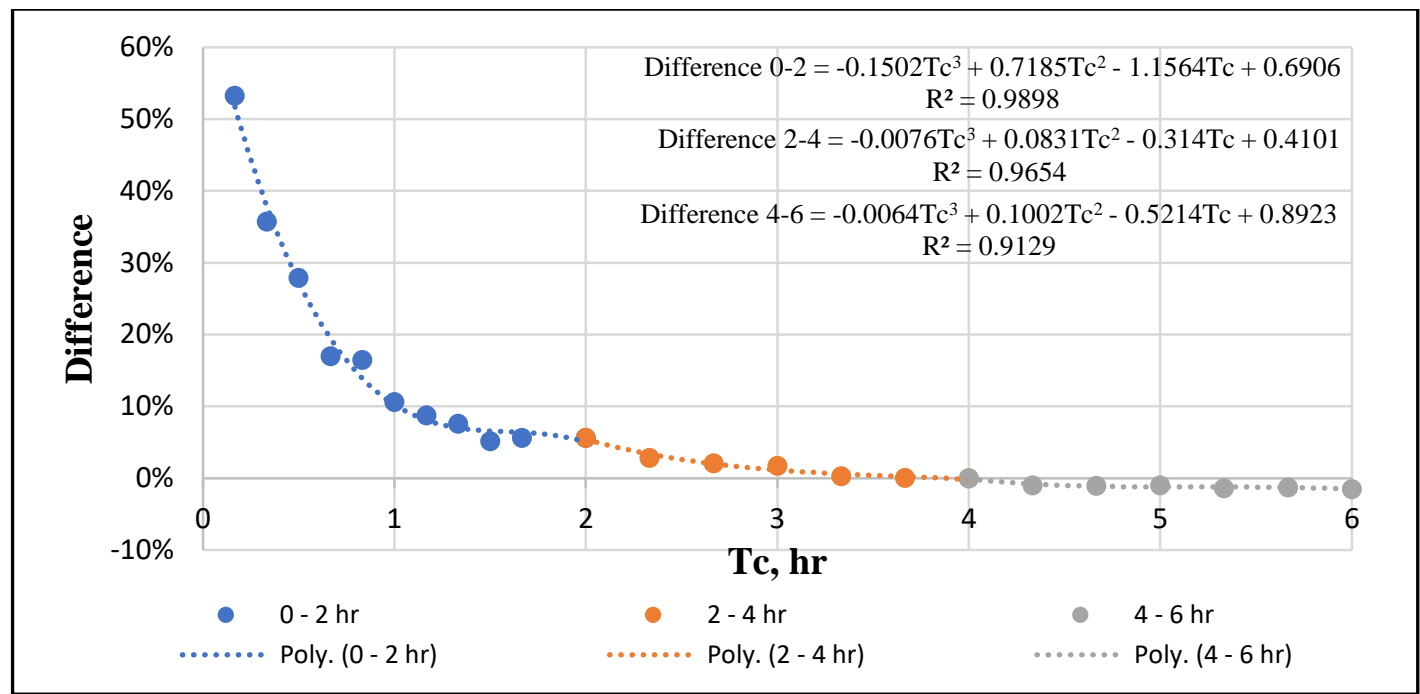

Fig 10. The Difference Till 6 hours at Return Period 50 Years

\subsection{At Return Period 20 Years}

Figure 11 illustrates the difference between the rational and SCS methods till 6 hours for the return period of 20 years. From the figure, it is found that the difference is great and decreases obviously for the time of concentration till 2 hours. For the time of concentration from 2 to 6 hours, the difference between the two methods is small (2\%: $8 \%)$. It is found that the difference has not a value zero during the 6 hours of the time of concentration.

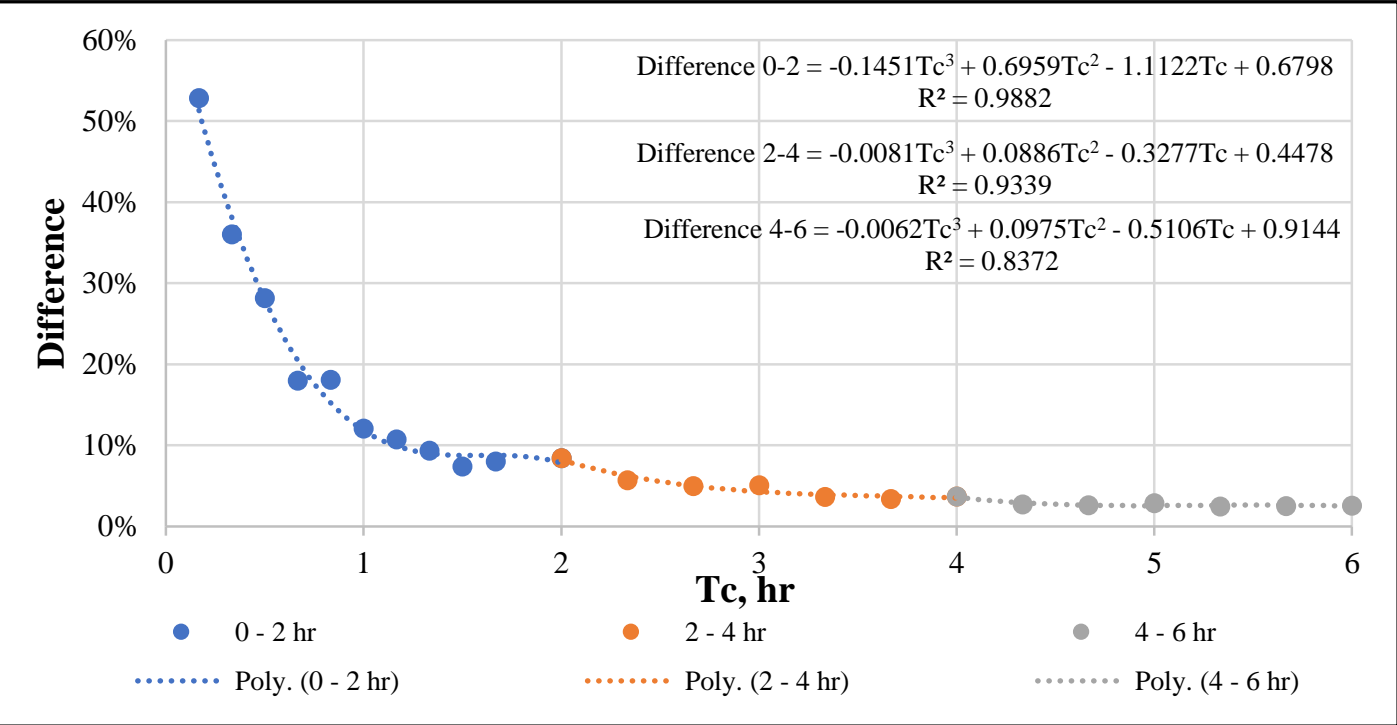

Fig 11. The Difference Till 6 hours at Return Period 20 Years

\subsection{At Return Period 10 Years}

Figure 12 illustrates the difference between the rational and SCS methods till 6 hours for the return period of 10 years. From the figure, it is found that the difference is great and decreases obviously for the time of concentration till 2 hours. For the time of concentration from 2 to 6 hours, the difference between the two methods is small (8\%: 12\%). It is found that the difference has not a value zero during the 6 hours of the time of concentration. 


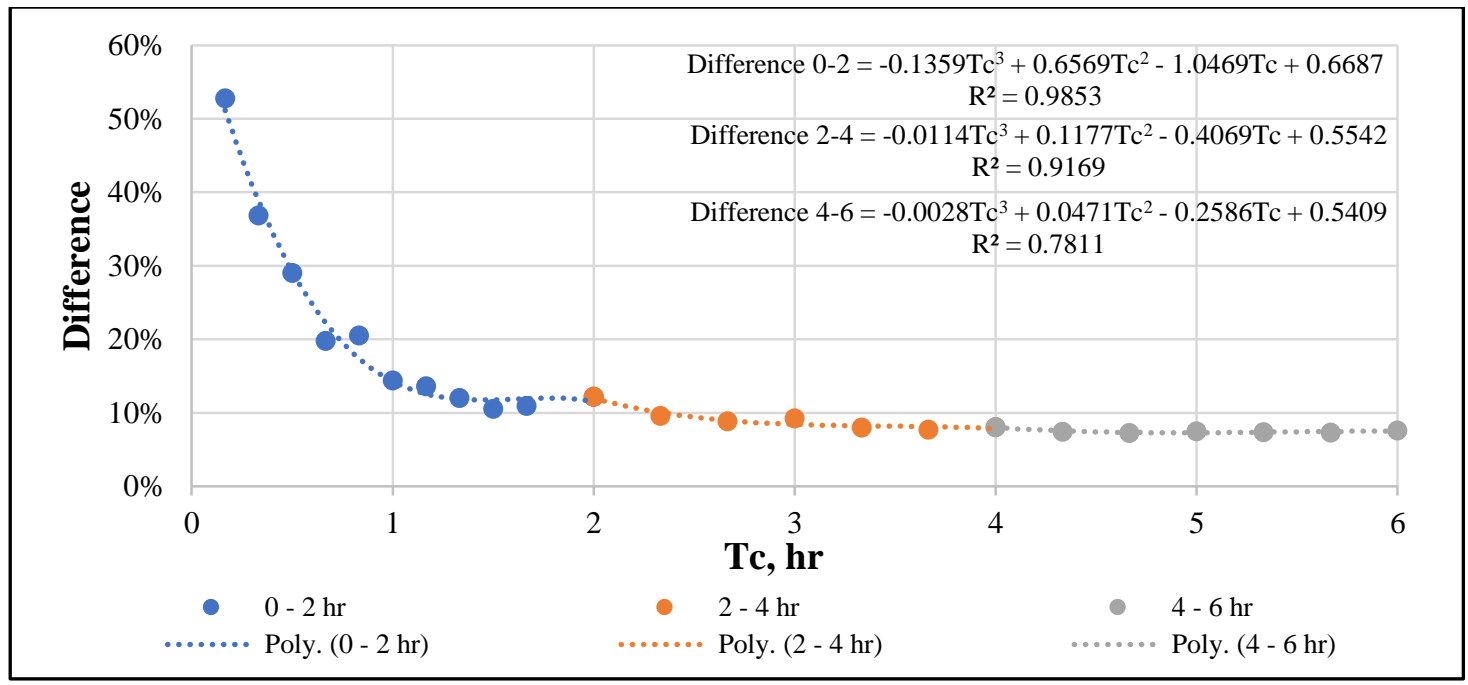

Fig 12. The Difference Till 6 hours at Return Period 10 Years

\subsection{At Return Period 5 Years}

Figure 13 illustrates the difference between the rational and SCS methods till 6 hours for the return period of 5 years. From the figure, it is found that the difference is great and decreases obviously for the time of concentration till 2 hours. For the time of concentration from 2 to 6 hours, the difference between the two methods is small (14\%: 18\%). It is found that the difference has not a value zero during the 6 hours of the time of concentration.

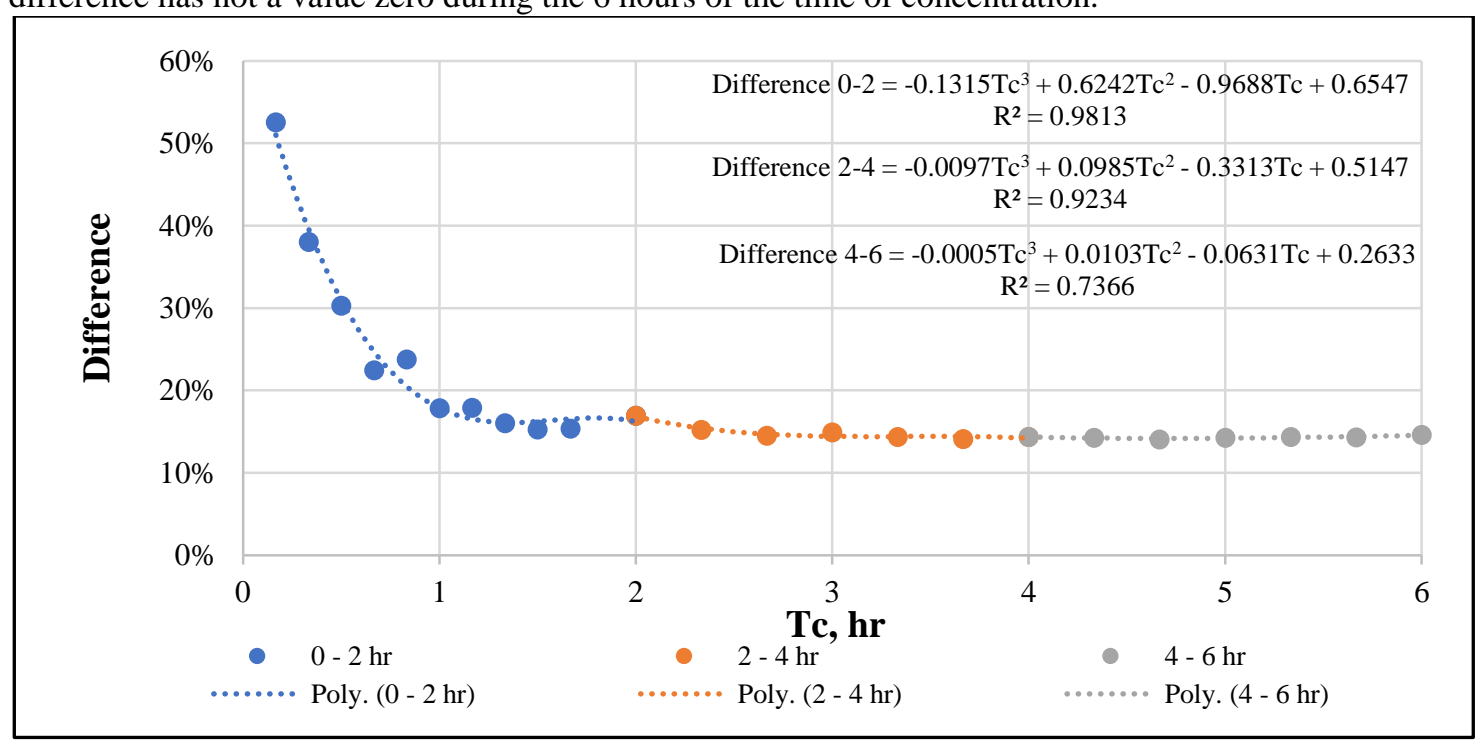

Fig 13. The Difference Till 6 hours at Return Period 5 Years

\subsection{At Return Period 2 Years}

Figure 14 illustrates the difference between the rational and SCS methods till 6 hours for the return period of 2 years. From the figure, it is found that the difference is great and decreases for the time of concentration till 2 hours. For the time of concentration from 2 to 6 hours, the difference between the two methods is small (30\%: $32 \%)$. It is found that the difference has not a value zero during the 6 hours of the time of concentration. 


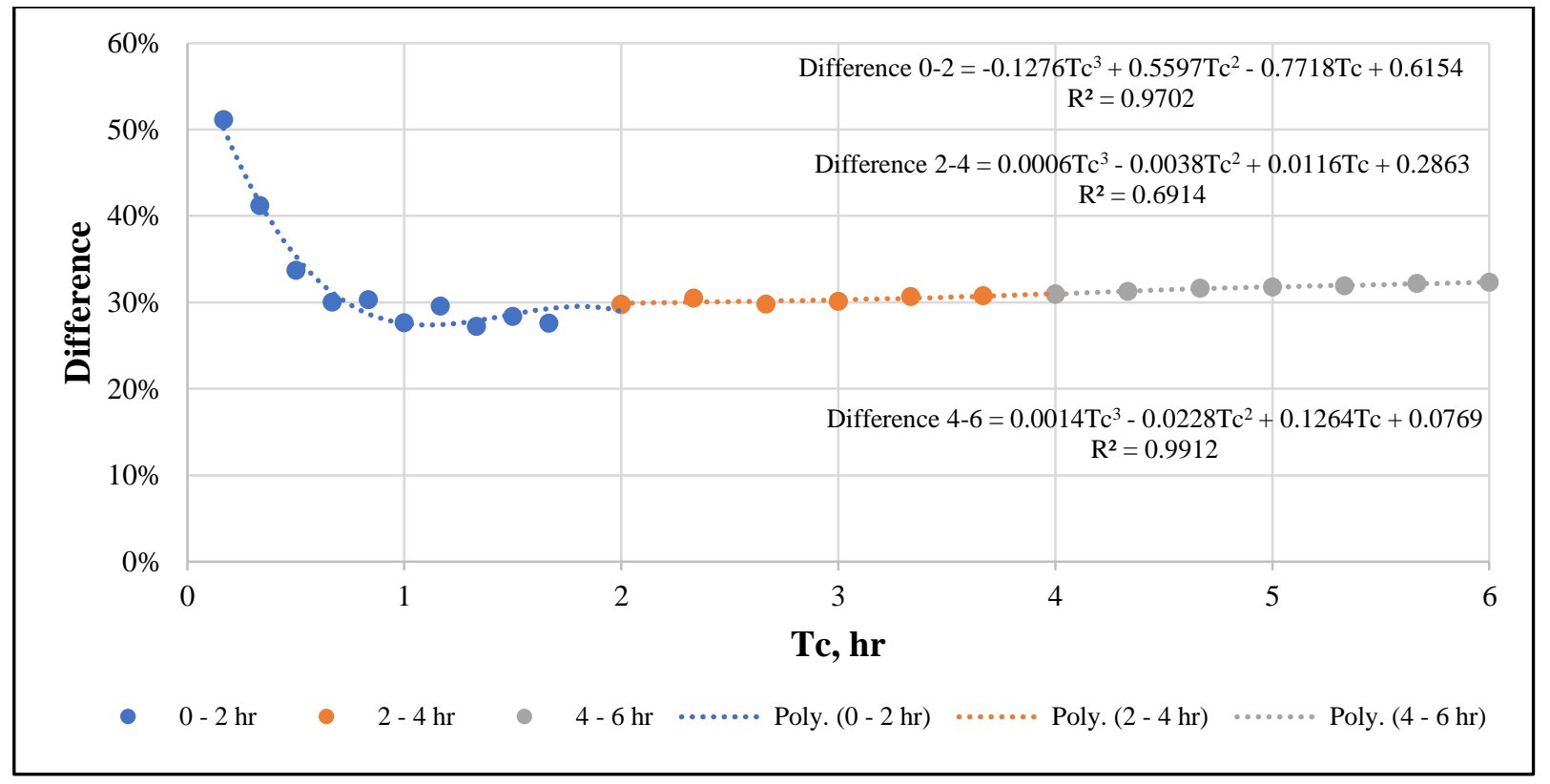

Fig 14. The Difference Till 6 hours at Return Period 2 Years

The average values for the difference between the rational and SCS methods for the three intervals of the time of concentration are provided in Fig 15 for the various return periods.

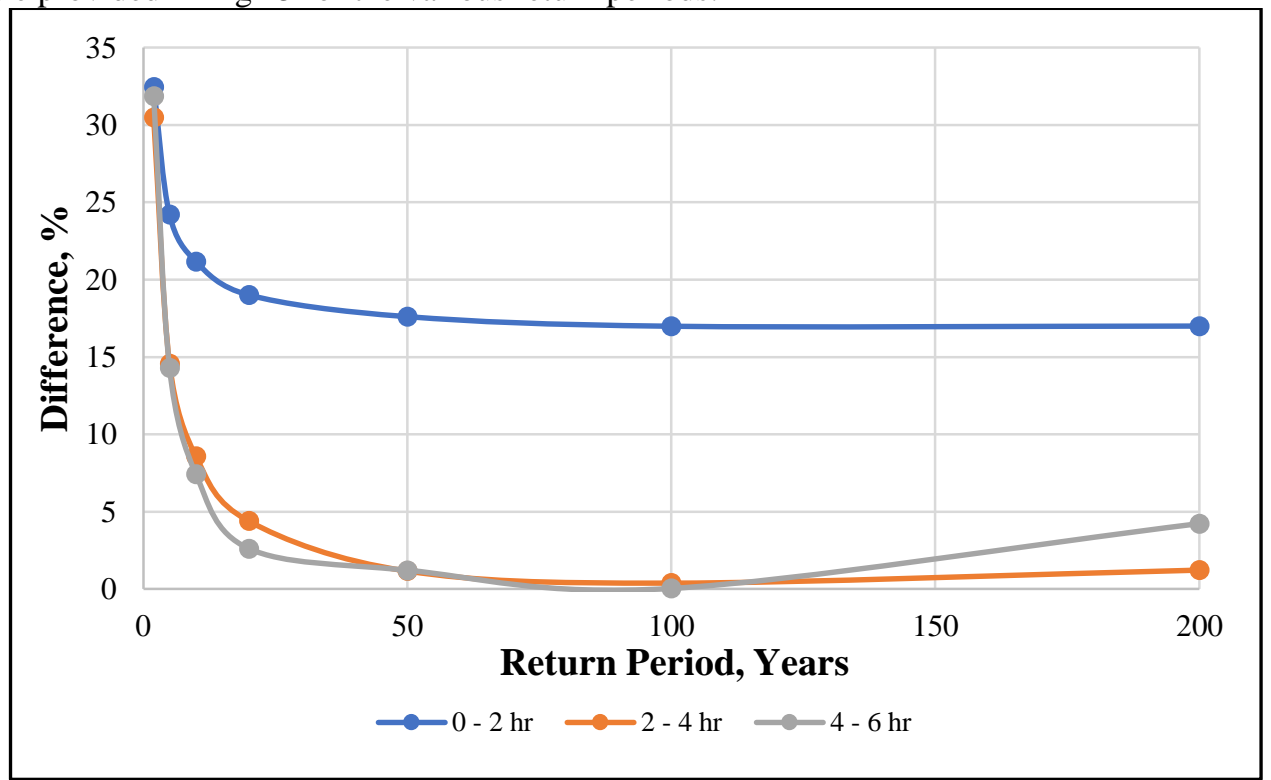

Fig 15. The Difference between the Rational and SCS Methods at Various Return Periods for Three Intervals of Time of Concentration

In general, the differences between the rational and the SCS method for all the return periods are equal to $21.19 \%$ for the time of concentration from 0 to $2 \mathrm{hr}, 8.68 \%$ for the time of concentration from 2 to $4 \mathrm{hr}$, and $8.81 \%$ for the time of concentration from 4 to $6 \mathrm{hr}$.

\section{CONCLUSION}

From the obtained results, it is concluded that the difference between the rational and SCS methods is great for the time of concentration till 2 hours, then it decreases obviously from 2 till 6 hours.

Also, it is concluded that the difference between the two methods is bigger for the small return periods of 2 and 5 years for all values of the time of concentration.

Employing the obtained equations, the peak runoff for one of the two methods (the rational and SCS methods) can be calculated knowing the time of concentration and the peak runoff for the second method. 


\section{REFERENCES}

[1] Hodgkins, G.A., Hebson, Charles, Lombard, P.J., and Mann, Alexander, "Comparison of peak-flow estimation methods for small drainage basins in Maine": U.S. Geological Survey Scientific Investigations Report -5170, 32pp. 2007

[2] Banasik, Kazimierz and Rutkowska, Agnieszka and Kohnová, Silvia ," Retention and Curve Number Variability in a Small Agricultural Catchment", The Probabilistic Approach.Open access journal Water:pp.1118 -1133, 2014

[3] Peter J. Coombes, Mark Babister, and Tony McAlister ."Is the Science and Data underpinning the Rational Method Robust for use in Evolving Urban Catchments", Australia , 2015

[4] R. Amutha. P. Porchelvan." Estimation of Surface Runoff in Malattar Sub-watershed using SCSCN Method". Journal Indian Soc. Remote Sens. No.37, pp.291-304, June 2009

[5] A.Majidi, M. Moradi, H. Vagharfard, A. purjenaie." Evaluation of Synthetic Unit Hydrograph (SCS) and Rational Methods in Peak Flow Estimation (Case Study: Khoshehaye Zarrin Watershed, Iran)", International Journal of Hydraulic Engineering., Vol 1, No5, pp.43-47,2012

[6] Maria Prama, Adel Omran, Dietrich Schröder, and Abdou Abouelmagd "Vulnerability assessment of fash foods in Wadi Dahab Basin, Egypt”. Environmental Earth Sciences ,pp.79:114, 2020

[7] Sara M. Abuzied and Basma M. H. Mansou. "Geospatial hazard modeling for the delineation of

flash flood-prone zones in Wadi Dahab basin, Egypt", Journal of Hydroinformatics",No.043.2018

[8] Abuzied, S. M., and Pradhan. "Hydro-geomorphic assessment of erosion intensity and sediment yield initiated debrisflow hazards at Wadi Dahab Watershed, Egypt". Journal of Georisk: Assessment and Management of Risk for Engineered Systems and Geohazards,pp. 1-26, 2020

[9] Ahmed A. Dakheel "Drawing Curves of The Rainfall Intensity Duration Frequency (IDF)and Assessment equation Intensity Rainfall for Nasiriyah City, Iraq", Journal of Thi-Qar University, Vol. 12 NO.2,pp. 63-87, 2018 